\title{
HEART RATE OVERSHOOT IN RUNNING EVENTS
}

\author{
K. YAMAJI, PhD* and R. J. SHEPHARD, MD, PhD** \\ *Faculty of Education, Toyama University, Toyama City, Japan \\ ** School of Physical and Health Education, University of Toronto, Toronto, Ontario, Canada
}

\begin{abstract}
The phenomenon of heart rate overshoot has been examined in 6 high-school athletes aged 15-16 years and in 8 university athletes aged $19-20$ years. The incidence was $100 \%$ over distances of 50,100 and 200 metres, and only one subject failed to show an overshoot following a $\mathbf{4 0 0}$ metre run. However, the overshoot was relatively larger and more long-lived following the shorter runs. While an accumulation of anaerobic metabolites seems the most likely explanation of the phenomenon over the longer distances, in the $\mathbf{5 0}$ metre event the Valsalva manoeuvre may also make some contribution.
\end{abstract}

Key words: Heart rate, Overshoot, Valsalva manoeuvre, Lactate accumulation, Isometric exercise, Isotonic exercise.

\section{INTRODUCTION}

Yamaji and Shephard (1985) previously demonstrated that the threshold intensity of effort needed to cause a postexercise overshoot of heart rate was as low as 140 beats/ min in some subjects. The incidence of overshoot increased with loading, reaching $65 \%$ with maximum aerobic work bouts. More recently, Yamaji and Shephard (1986) noted that the incidence of overshoot further increased to $65-95 \%$ following one minute bouts and to $95-100 \%$ following more intensive $10 \mathrm{sec}$ bouts of supramaximal work on the cycle ergometer.

McArdle et al (1967) looked at brief running events, and found an overshoot following a 60 yard ( 55 metre) dash, but not following longer running events. The purpose of the present study was to re-examine the extent of heart rate overshoot following four running events $(50 \mathrm{~m}, 100 \mathrm{~m}, 200$ $\mathrm{m}$, and $400 \mathrm{~m}$ ).

\section{METHODS AND PROCEDURES}

\section{Subjects}

The subjects were six senior high school students aged 15 to 16 years, and 8 university students aged 19 or 20 years. The former had recently joined the track and field club at

Address for correspondence:

Prof. R. J. Shephard

School of Physical and Health Education

University of Toronto

Ontario

Canada their school. The latter had trained 2 to 3 times per week for 2-5 years as members of the track and field club at their university, but were not elite sprinters. Physical characteristics and track times are summarised in Table I.

\section{Exercise}

The subjects warmed up as for a normal race. Then they ran the four selected distances $(50,100,200$ and 400 metres) at maximum speed under close to actual race conditions. Immediately after completing each distance, they stopped in a standing position for about 30 seconds while the recovery electrocardiogram was recorded. The order of the required tests was $50,100,200$ and $400 \mathrm{~m}$ throughout, but an adequate recovery time of $20-30 \mathrm{~min}$ was allowed between each test.

\section{Heart Rate Measurements}

The electrocardiogram was recorded by telemetry $\left(\mathrm{CM}_{5}\right.$ leads) at $50 \mathrm{~mm} / \mathrm{sec}$. All participants showed a normal rhythm and waveform during all tests. A "Digitimatic" caliper (Mitutoya, Japan) was used to measure R-R intervals in successive groups of three. Readings were taken to the nearest $0.1 \mathrm{~mm}$, all values being converted to the corresponding instantaneous heart rates.

\section{RESULTS}

A typical heart rate pattern prior to, during and following the four running bouts is illustrated in Fig. 1. There was an anticipatory increase of rate prior to each event. The heart rate increased rapidly during the initial stages of each

TABLE I

Physical characteristics of subjects and time for all running events

\begin{tabular}{|c|c|c|c|c|c|c|c|c|c|}
\hline \multirow{2}{*}{\multicolumn{2}{|c|}{ Subjects }} & & \multirow[b]{2}{*}{$\begin{array}{l}\text { Age } \\
\text { (yrs) }\end{array}$} & \multirow[b]{2}{*}{$\begin{array}{l}\text { Height } \\
\text { (cm) }\end{array}$} & \multirow[b]{2}{*}{$\begin{array}{c}\text { Weight } \\
\text { (kg) }\end{array}$} & \multirow[b]{2}{*}{$\begin{array}{l}50 \mathrm{~m} \\
(\mathrm{sec})\end{array}$} & \multicolumn{3}{|c|}{ Mean times } \\
\hline & & & & & & & $\begin{array}{c}100 \mathrm{~m} \\
(\mathrm{sec})\end{array}$ & $\begin{array}{c}200 \mathrm{~m} \\
(\mathrm{sec})\end{array}$ & $\begin{array}{c}400 \mathrm{~m} \\
(\mathrm{sec})\end{array}$ \\
\hline \multirow[t]{3}{*}{ Senior high school students } & $(n=6)$ & Mean & 15.8 & 166.2 & 55.7 & 6.9 & 13.0 & 26.4 & 62.1 \\
\hline & & Range & $(15-16)$ & (161-173) & $(47-68)$ & $(6.2-7.2)$ & $(12.4-13.4)$ & $(24.9-27.7)$ & $(58.4-66.6)$ \\
\hline & & S.D. & 0.4 & 3.6 & 6.9 & 0.2 & 0.7 & 1.7 & 2.9 \\
\hline \multirow[t]{3}{*}{ University students } & $(n=8)$ & Mean & 19.9 & 170.8 & 61.3 & 6.5 & 11.9 & 24.4 & 54.6 \\
\hline & & Range & $(19-20)$ & $(161-177)$ & $(49-66)$ & $(6.2-6.9)$ & $(11.4-12.3)$ & $(23.1-25.7)$ & $(51.8-58.6)$ \\
\hline & & S.D. & 0.3 & 5.8 & 5.2 & 0.2 & 0.3 & 0.9 & 2.2 \\
\hline
\end{tabular}




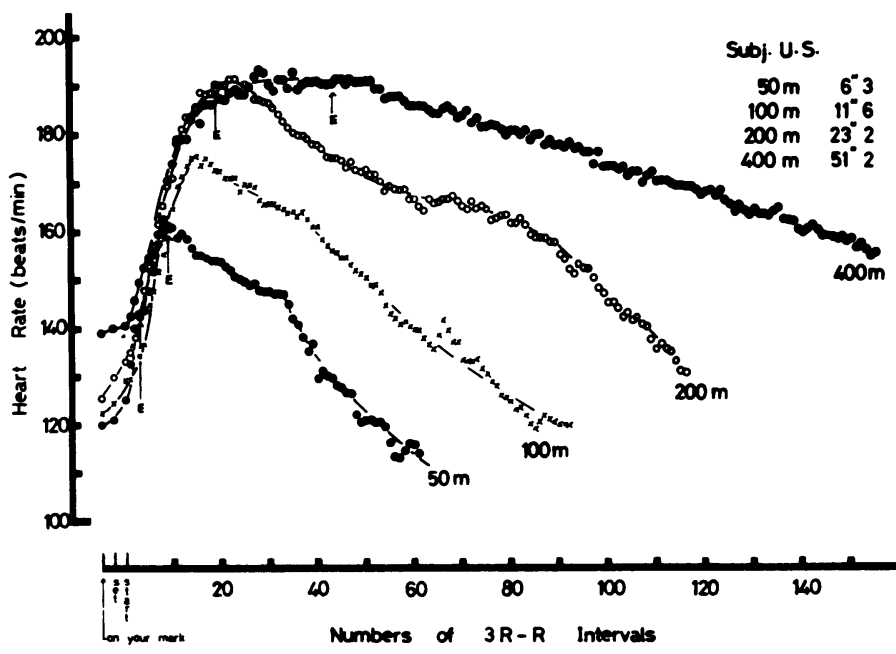

Fig. 1: Heart rate in anticipation of and during $50 \mathrm{~m}, 100 \mathrm{~m}, 200 \mathrm{~m}$ and $400 \mathrm{~m}$ running events and during recovery in Subject U.S. E indicates the end of the run.

running bout, and then climbed progressively towards a maximum as each run proceeded. The longer running events tended to elicit higher peak heart rates than the shorter races, and a plateau was approached in the latter stages of the $400 \mathrm{~m}$ run.

In general, an overshoot was seen following all four runs. However, the duration of this phenomenon was greater following the shorter runs than after the longer events. Moreover, in the older students, the rate of increase of heart rate during recovery was also somewhat greater for the shorter events (Figs. 2 and 3). The relative magnitude of the overshoot (expressed as a percentage of the immediate end-exercise value) was less over the longer running distances; in other words, the heart rate-overshoot was more marked and longer-lived after the shorter running events (Figs. 4 and 5). However, there was little difference in the peak heart rate or the relative overshoot between the $200 \mathrm{~m}$ and the $400 \mathrm{~m}$ running events.

The peak heart rate was reached as late as 15 to 21 beats following the $50 \mathrm{~m}$ dash and the $100 \mathrm{~m}$ sprint, but occurred only 6 beats after the 200 and $400 \mathrm{~m}$ races.

The overshoot was more marked for both the high school and the university athletes following the shorter runs. In the 50 metre event, all 14 subjects showed an overshoot from the fourth to the tenth 3 heart-beat interval, 9 of 14 still showed an overshoot at the twentieth such interval, and 3 of 14 at the thirtieth interval. For the 100 metre event, all 14 subjects developed an overshoot from the second to the fourth interval, 11 of the 14 still showed this at the tenth interval, and the final overshoot (2 of 14) was seen at the twentieth interval. After the $\mathbf{2 0 0}$ metre event, 12 of 14 subjects demonstrated an overshoot in the second interval, but the proportion dropped to 2 of 14 by the tenth interval, with no overshoot beyond the twelfth interval. The pattern was rather similar for the $\mathbf{4 0 0}$ metre event, 10 of 14 subjects having an overshoot in the second and third intervals, 2 of 14 in the tenth interval, and none thereafter.

\section{DISCUSSION}

It is now well recognised that if the instantaneous heart rate is calculated from the $R-R$ intervals following vigorous

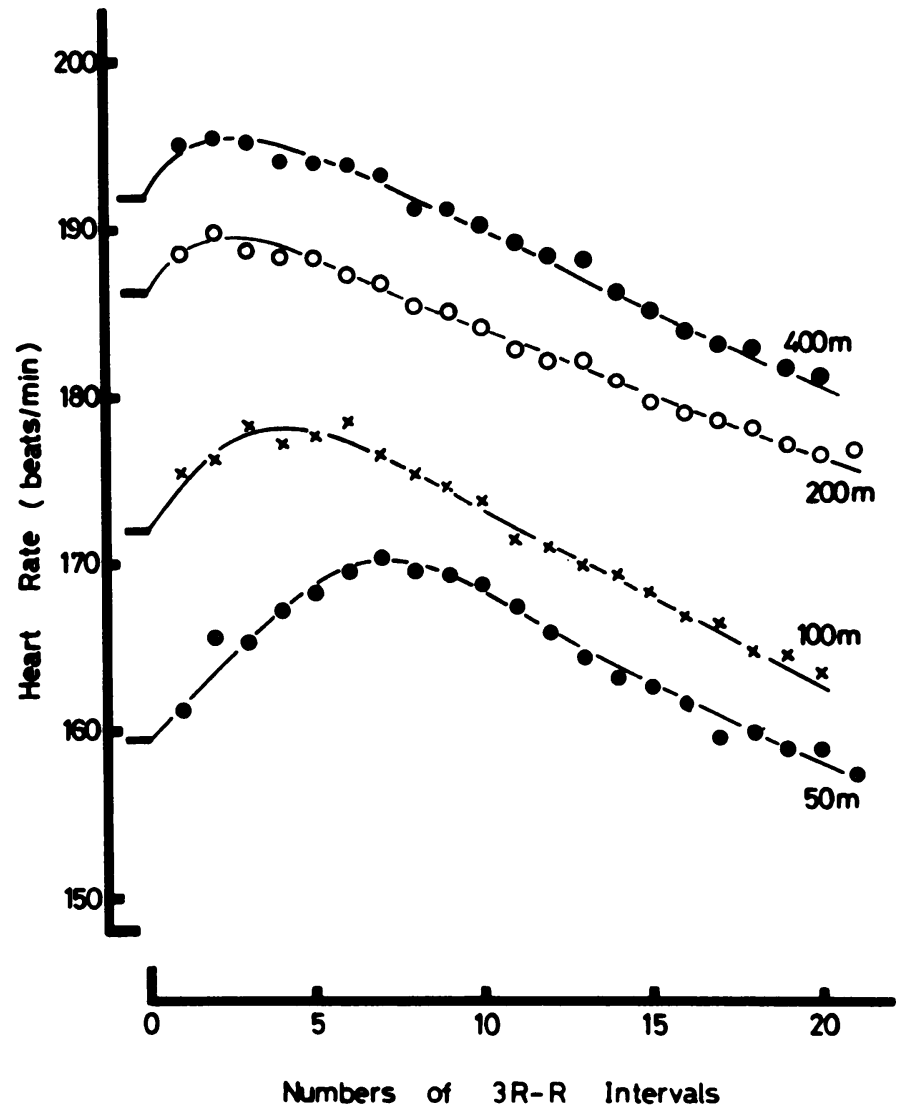

Fig. 2: Instantaneous heart rate following $50 \mathrm{~m}, 100 \mathrm{~m}, 200 \mathrm{~m}$ and $400 \mathrm{~m}$ running events. Average data for 6 senior high school students.

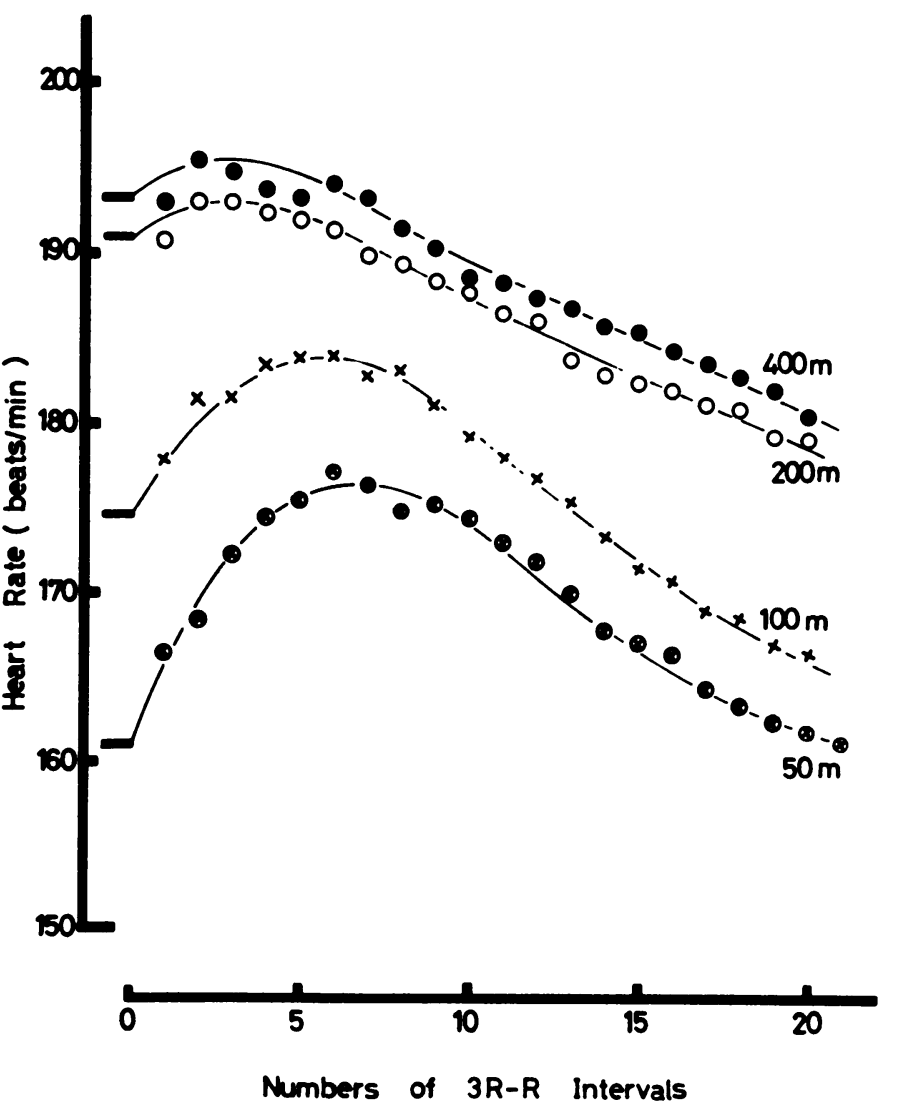

Fig. 3: Instantaneous heart rate following $50 \mathrm{~m}, 100 \mathrm{~m}, 200 \mathrm{~m}$ and $400 \mathrm{~m}$ running events. Average data for 8 university students. 


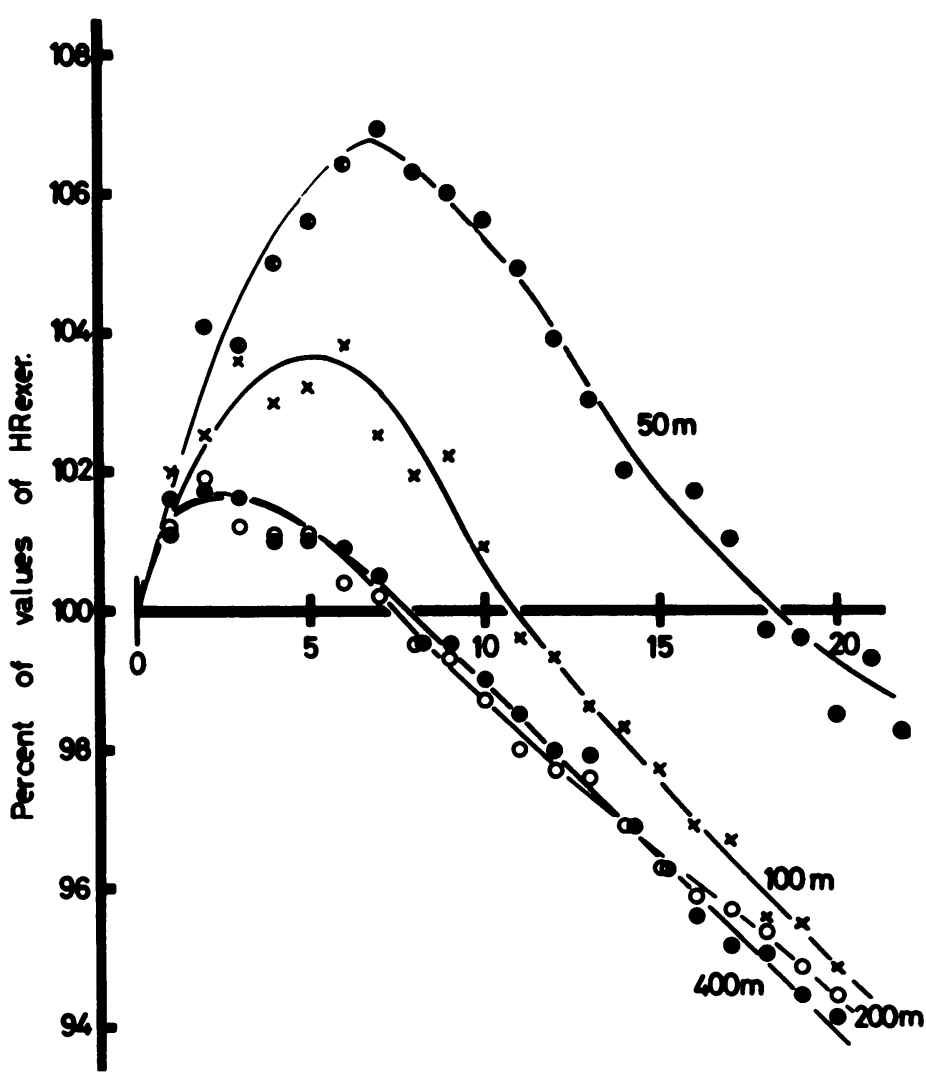

Fig. 4: Instantaneous heart rate following $50 \mathrm{~m}, 100 \mathrm{~m}, 200 \mathrm{~m}$ and $400 \mathrm{~m}$ running events in senior high school students. All values expressed as per cent of values seen in the final three beats of exercise.

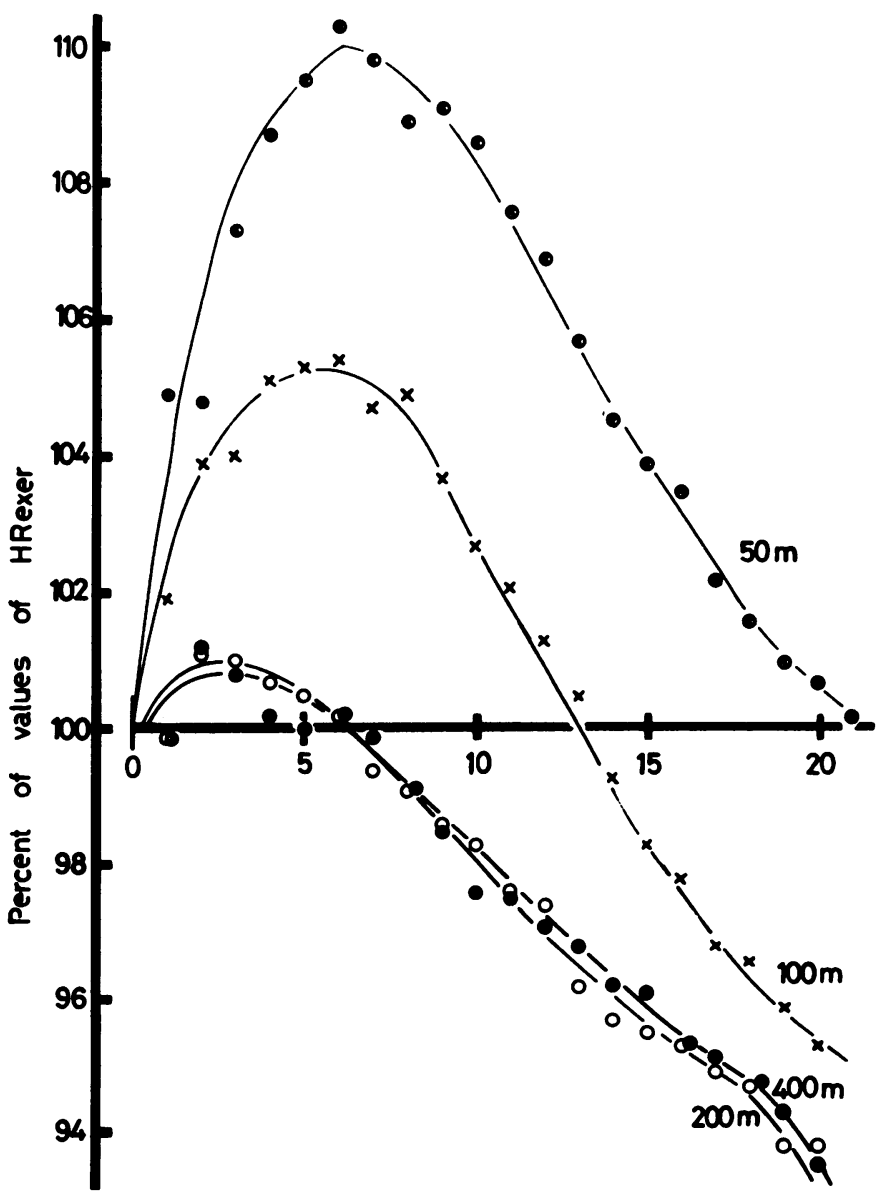

Fig. 5: Instantaneous heart rate following $50 \mathrm{~m}, 100 \mathrm{~m}, 200 \mathrm{~m}$ and $400 \mathrm{~m}$ running events in university students. All values expressed as per cent of values seen in the final three beats of exercise. Abscissa shows number of 3, $R-R$ intervals. exercise, a proportion of subjects show a heart rate overshoot following both submaximal and maximal aerobic work (Yamaji and Shephard, 1985). The phenomenon is more consistently observed following anaerobic work, where a steady state cannot be reached during activity (Yamaji and Shephard, 1986). Indeed, in the earlier study of track performance, McArdle et al (1967) were able to show an overshoot following a 60 yard $(55 \mathrm{~m})$ dash, but not following 220 yard $(201 \mathrm{~m}), 440$ yard $(402 \mathrm{~m}), 880$ yard $(804 \mathrm{~m})$. 1 mile $(1609 \mathrm{~m})$ and 2 mile $(3218 \mathrm{~m})$ runs.

Perhaps because of the more detailed analysis permitted by our methodology, and perhaps because our subjects were less skilful in developing all-out effort while running, we observed an overshoot in all events except for the $400 \mathrm{~m}$ race in subject T.K. His heart rate reached 203 beats $/ \mathrm{min}$ during the $\mathbf{4 0 0} \mathrm{m}$ run; this value was close to his personal maximum steady state reading, thus leaving little potential for observation of an overshoot. Our previous studies of cycle ergometry (Yamaji et al, 1984) also noted that when the heart rate was high, it was less likely that an overshoot would be observed.

Possible causes of a heart rate overshoot following anaerobic exercise include (1) performance of a Valsalva manoeuvre (McArdle and Foglia, 1969), (2) accumulation of metabolites due to a relative under-perfusion of the active muscles (Kay and Shephard, 1969), (3) a lag in feedback mechanisms regulating heart rate, (4) a delay in the increase of parasympathetic activity or the decrease of sympathetic activity after exercise, (5) a reflex stimulation of heart rate by aortic baro-receptors, as blood pools in the inactive lower limbs (McArdle et al, 1967), or (6) some form of respiratory arrhythmia.

Comparison of overshoot for the four events is complicated a little by the consistent ordering of the four experiments. However, since the first race was preceded by a warm-up, the exercise prior to the other events can also be considered as a warm-up. A second problem is that the absolute heart rate is higher immediately following the longer runs, so that in terms of debt repayment, flow is likely to be greater, irrespective of the existence of any overshoot. Moreover, as already noted, in some subjects the heart rate following the $\mathbf{4 0 0}$ metre run is already so high that there is little possibility of a further increase. Despite these qualifications, there seems little question that the overshoot phenomenon is more marked for short than for long duration runs.

McArdle and Foglia (1969) suggested that the cause of overshoot in isometric activities was the performance of a Valsalva manoeuvre. Yamaji and Shephard (1986) previously observed a $72.7 \%$ incidence of heart rate overshoot for isometric knee extension at $70 \%$ MVC, while that for isotonic extension was only $7.7 \%$. It is also wellrecognised that some champion sprinters do not take a breath during very brief events. However, it is difficult to hold a breath for more than 10 seconds when exercising hard. Part of the difference between the long and the short sprints may thus be traced to this cause. The accumulation of anaerobic metabolites could contribute to overshoot in the longer events, and as indicated the longer runs do give rise to a greater recovery tachycardia. There seems no reason why respiratory arrythmia or the lag in feedback mechanisms and autonomic adjustments should differ 
between the four types of event. However, the extent of peripheral pooling should have been greater after the longer events, because of a larger accumulation of metabolites and a greater rise of local temperature. We thus conclude that the main reasons for the course of heart rate recovery that we observed were a combination of the local accumulation of metabolites and (in the shorter events) the possible performance of a Valsalva manoeuvre.

\section{References}

Kay, C. and Shephard, R. J., 1969 "On muscle strength and the threshold of anaerobic work". Int.Z.angew.Physiol. 27: 311-328.
McArdle, W. D. and Foglia, G. F., 1969 "Energy cost and cardiorespiratory stress of isometric and weight training exercises". J.Spt.Med.Phys. Fitness 9: 23-30.

McArdle, W. D., Foglia, G. F. and Patti, A. V., 1967 "Telemetered cardiac response to selected running events". J.Appl.Physiol. 23: 566-570.

Yamaji, K. and Shephard, R. J., 1985 "Incidence of heart rate overshoot in maximal and sub-maximal exercise". Int J.Spts Cardiol. 2: 38-42.

Yamaji, K. and Shephard, R. J. (in press). Incidence of heart rate overshoot in $10 \mathrm{sec}$ and one minute supramaximal work on a cycle ergometer". J.Spt.Med.Phys.Fitness.

Yamaji, K., Mano, S., Nada, H., Yamanishi,J. and Shephard, R. J. (in press). "Incidence of heart rate overshoot following sustained isometric and repeated isotonic arm flexion and knee extension at various \% of MVC". J.Spt.Med.Phys.Fitness.

Yamaji, K., Onodera, K. and Kitamura, K., 1984 "Incidence of overshoot in relation to the magnitude of maximal heart rate on a cycle ergometer". Japanese J.Phys. Educ. (Hokuriku) 21: 71-75.

\section{LATE NOTICES}

\section{Multidisciplinary International Congress \\ MOVEMENT AND SPORT IN WOMEN'S LIFE \\ 17th-21st August, 1987 \\ Held at the University of Jyväskylä}

The congress is organised by the Faculty of Physical and Health Education, Foundation for the Promotion of Physical Culture and Health and the City of Jyväskylä. It is endorsed by ICSSPE, FIEP and IAPESGW.

Further details from: Jyväskylä Congress - on Movement and Sport in Women's Life, Faculty of Physical and Health Education, University of Jyväskylä, 40100 JYAASKYLÄ, Finland

\section{INTERNATIONAL SPORTS MEDICINE CONGRESS ON SOCCER \\ 12th and 13th September, 1986}

\section{AFC "AJAX" in conjunction with St. Lucas's Hospital, Amsterdam and the University of Maastricht}

In this congress many aspects of football and medicine will be discussed, especially traumatology and advanced (arthroscopic) surgery, prevention and rehabilitation, medical organisation, youth sports and advanced physiotherapy.

The languages are English and Dutch. The Registration Fee will be Dfl. 250,00.

Registration and information: AFC "AJAX", Middenweg 401, 1098 AV Amsterdam, The Netherlands. Phone: 020-946515. 